\title{
BMJ Open Taking stock of vaccine hesitancy among migrants: a scoping review protocol
}

\author{
Akhenaten Siankam Tankwanchi (D) , ${ }^{1}$ Anelisa Jaca (D) ,2 Heidi J Larson, ${ }^{3,4}$ \\ Charles S Wiysonge (1) , ${ }^{2,5,6}$ Sten $\mathrm{H}$ Vermund (1) ${ }^{7}$
}

To cite: Tankwanchi AS, Jaca A, Larson HJ, et al. Taking stock of vaccine hesitancy among migrants: a scoping review protocol. BMJ Open 2020;10:e035225. doi:10.1136/ bmjopen-2019-035225

- Prepublication history for this paper is available online To view these files, please visit the journal online (http://dx.doi. org/10.1136/bmjopen-2019035225).

Received 25 0ctober 2019 Revised 25 April 2020 Accepted 27 April 2020

\section{Check for updates}

(c) Author(s) (or their employer(s)) 2020. Re-use permitted under CC BY-NC. No commercial re-use. See rights and permissions. Published by BMJ.

For numbered affiliations see end of article.

Correspondence to Dr Akhenaten Siankam Tankwanchi; abs.tankwanchi@gmail.com

\section{ABSTRACT}

Introduction At the 72nd World Health Assembly of May 2019, WHO member states prioritised a global action plan to promote migrant and refugee health. Five months earlier, WHO had declared vaccine hesitancy-the reluctance to vaccinate despite the availability of vaccination services—as one of the top 10 threats to global health. Although vaccination is often a requirement for immigration, repeated outbreaks of vaccine-preventable diseases within certain immigrant communities in some host nations suggest that vaccine hesitancy could be a factor in their susceptibility to vaccine-preventable diseases. Studies of the prevalence and determinants of vaccine hesitancy among migrants globally seem to be lacking. This scoping review will (1) identify articles on vaccine hesitancy among migrants; (2) examine the extent and nature of the extant evidence; and (3) determine the value of undertaking a full systematic review.

Methods and analysis The framework for the scoping review proposed by the Joanna Briggs Institute will be used. The reporting will follow the Preferred Reporting Items for Systematic Reviews and Meta-Analyses extension for Scoping Reviews checklist. Studies published in English or French between January 1999 and December 2019 will be drawn from most or all of the following multidisciplinary databases: Africa-Wide Information, Allied and Complementary Medicine, Cochrane Library, Cumulative Index of Nursing and Allied Health Literature, Embase, Index Medicus for the Eastern Mediterranean Region, International Bibliography of Social Sciences, Literature in the Health Sciences in Latin America and the Caribbean, Medline, Proquest Theses/Dissertations, Psyclnfo and Web of Science. The search will include an extensive list of keywords to capture multiple dimensions of confidence and hesitancy vis-à-vis vaccines among migrants. Findings will be reported through summary narratives, tables, flowcharts and evidence maps. Ethics and dissemination This review is exempted from ethical approval and will be published in a peer-reviewed open-access journal to ensure wide dissemination.

\section{INTRODUCTION}

Disparities in opportunity structures often compel people to move, internally or internationally. Therefore, migration is a universal phenomenon that affects most countries.

\section{Strengths and limitations of this study}

This review will synthesise evidence of vaccine hesitancy among migrants over two decades.

- This review will glean out evidence from all WHO regions.

- This review will include both qualitative and quantitative studies published in English or French.

- The search, synthesis, and reporting of evidence will be guided by recommendations from the Joanna Briggs Institute and the Preferred Reporting Items for Systematic Reviews and Meta-Analyses extension for Scoping Reviews checklist.

- One possible limitation of this review is the potential exclusion of important studies not published in English or French.

Migrants are driven by many factors including the prospects of improving their access to work, civil, political and religious rights, security and healthcare. ${ }^{1}$ One important aspect of healthcare that may affect migration is immunisation. People are often required to vaccinate in order to immigrate..$^{2-4}$ In contrast, access to vaccination and continuity of care are more challenging for people on the move such as migrants, refugees or nomadic populations. ${ }^{56}$ Long after they have settled in the host country, vaccination coverage among migrants may still be suboptimal when compared with that of the general population. ${ }^{78}$ Vaccine sceptics and populist politicians in some host countries openly challenge the scientific consensus about the effectiveness and safety of vaccination. ${ }^{9-11}$ As a result, some migrants with pre-established concerns about vaccination may see their concerns reinforced, whereas others may succumb to anti-immunisation messaging and begin to question the benefits of some vaccines. The repeated measles outbreaks among SomaliAmericans are instructive. ${ }^{12-14}$

Measles, a highly contagious respiratory disease and the leading cause of 
vaccine-preventable infant mortality worldwide, was declared eliminated in the USA in $2000 .{ }^{12}$ Since the elimination, however, several outbreaks have occurred in various US states with index cases often linked to overseas travels. ${ }^{13-15}$ In 2011 and 2017, two measles outbreaks with a total number of 100 cases, $72 \%$ of which were members of the Somali community of Hennepin County, Minnesota, occurred in the USA. ${ }^{1617}$ Prior to the 2011 outbreak, measles-mumps-rubella (MMR) vaccine coverage among 2-year-old Somali children in Minnesota had declined significantly from $>91 \%$ in 2004 to $54 \%$ in 2010 , as Somali parents began refusing MMR vaccine for their children owing to concerns of high autism rate in their community. ${ }^{11} 18$ By 2014, MMR vaccine uptake was down to $42 \%$ among 2-year-old Somali Minnesotan children. ${ }^{17}$ Many of these vaccine concerns and fears were also fuelled by local antivaccine activists and the author of a currently discredited Lancet study, now retracted, which associated the MMR vaccine with the development of autism. ${ }^{19} 20$

Likewise, during a 2011 measles outbreak in Norway, 8 of 10 cases $(80 \%)$ identified were from the Somali community of Oslo. ${ }^{21}$ Although there is evidence of low measles vaccine uptake among Somali migrants in the USA and Norway, we do not currently know how prevalent this issue is among Somalis living in other Western nations or nonWestern host countries with a much larger Somali diaspora (eg, Ethiopia, Kenya and Yemen). It is also unclear whether, and if so why, Somali migrants might be more represented among non-vaccinators than other African migrants. Emerging evidence from England reveals that human papillomavirus (HPV) vaccine acceptance could be very low among UK-based immigrant parents from Eastern, Southern and Western Africa due to fears that their young daughters might become promiscuous and even infertile after HPV vaccination. ${ }^{22}$

When vaccination services are available yet underutilised and barriers to access are reduced, then psychosocial

\section{Table 1 PICO elements for study selection criteria}

\begin{tabular}{|c|c|c|c|}
\hline $\begin{array}{l}\text { Participant/ } \\
\text { population }\end{array}$ & Intervention & Comparators & Outcomes \\
\hline $\begin{array}{l}\text { Diaspora, } \\
\text { émigrés, } \\
\text { emigrants, } \\
\text { migrants, } \\
\text { immigrants, } \\
\text { refugees, } \\
\text { foreigners, } \\
\text { foreign-born, } \\
\text { newcomers }\end{array}$ & $\begin{array}{l}\text { Immunization, } \\
\text { vaccination, } \\
\text { vaccine-related } \\
\text { communication }\end{array}$ & $\begin{array}{l}\text { General } \\
\text { population, } \\
\text { non-migrant, } \\
\text { local, native } \\
\text { population, no } \\
\text { comparator }\end{array}$ & $\begin{array}{l}\text { Vaccine } \\
\text { confidence, } \\
\text { vaccine } \\
\text { uptake, } \\
\text { vaccine } \\
\text { refusal, } \\
\text { vaccine } \\
\text { hesitancy, } \\
\text { vaccine } \\
\text { delay, missed } \\
\text { schedule } \\
\text { of vaccine, } \\
\text { non-medical } \\
\text { vaccination } \\
\text { exemption }\end{array}$ \\
\hline
\end{tabular}

PICO, Participants, Intervention, Comparators and Outcome. processes more so than structural factors may better explain low vaccination uptake. One such factor that conspires against universal vaccination coverage and is gaining currency in the literature is 'vaccine hesitancy'. ${ }^{23}$ Broadly defined as the reluctance to vaccinate despite the availability of vaccination services, vaccine hesitancy entails a continuum of complex and contextspecific attitudes and behaviours, ranging from total acceptance to complete refusal, and varying across time, place and vaccines. Underlying factors of hesitancy are issues of confidence, complacency and convenience. ${ }^{24}{ }^{25}$ The authoritative working group on vaccine hesitancy appointed by the WHO's Strategic Advisory Group of Experts on Immunization (SAGE) has developed a multilevel explanatory model of vaccine hesitancy encompassing contextual influences (eg, religion, communication and media environment, politics and so on), individual/group factors (eg, beliefs, attitudes and motivation about health, trust in health system, past experience with vaccination, peer influence and so on), and vaccine-specific and vaccination-specific determinants (eg, cost, vaccination schedule, mode of administration and so on).$^{24}$ Vaccine hesitancy theories and models may help to explain why some vaccine-hesitant individuals may accept all vaccines but remain concerned or unsure about vaccines, may shun or delay some vaccines yet accept others, or may refuse all vaccines. ${ }^{25-29}$

As a core topic, vaccine hesitancy is relatively new, with only six articles using the phrase in either the title or abstract between 2009 and $2011 .^{29}$ Even its definition is still evolving while its qualification as a behaviour has been called into question. ${ }^{30}{ }^{31}$ Yet, the resurgence and repeated outbreaks of vaccine-preventable diseases like measles that were considered eliminated in some Western countries have prompted WHO to declare vaccine hesitancy as one of the world's top 10 threats to global health in $2019 .{ }^{32}$ If vaccine hesitancy is indeed a global threat to health and if migrant communities are potential 'hotspots' for vaccine hesitancy, then its prevalence and determinants within these communities must be examined. The overall aim of this scoping review is to take stock of the current evidence of vaccine hesitancy among migrants. Toward this end, the proposed review will address the following objectives:

1. Identify evidence of vaccine hesitancy among migrant individuals and communities.

2. Examine the extent and nature of the extant evidence.

3. Determine the value of undertaking a full systematic review.

Given the relative recency of vaccine hesitancy as a research area and given that we are not aware of any comprehensive evidence of vaccine hesitancy among migrant populations, the previously mentioned objectives are suitable and consistent with the 'reconnaissance' purpose of the scoping review. ${ }^{33}$ Scoping will also allow us to identify and define crucial concepts, gaps in the literature, and types and sources of evidence to inform practice, policy and research. ${ }^{33}$ In choosing to focus on vaccine hesitancy, neither do we imply nor believe that 
Table 2 Keywords and draft PMC search strategy for literature review on vaccine hesitancy

\begin{tabular}{|c|c|c|c|c|}
\hline Intervention & Population & Outcome & PMC search details & $\begin{array}{l}\text { Items (n) } \\
\text { found in } \\
\text { MEDLINE }\end{array}$ \\
\hline $\begin{array}{l}\text { Vaccination, } \\
\text { vaccine, } \\
\text { Immunisation, } \\
\text { immunization }\end{array}$ & $\begin{array}{l}\text { Diaspora, } \\
\text { émigré, } \\
\text { emigrant, } \\
\text { foreigner, } \\
\text { immigrant, } \\
\text { migrant, } \\
\text { refugee }\end{array}$ & $\begin{array}{l}\text { Acceptance, uptake, confidence, } \\
\text { trust, anxiety, doubt, mistrust, } \\
\text { anti-vaccination, anti-vax, } \\
\text { concern, distrust, misinformation, } \\
\text { resistance, compulsory, dropout, } \\
\text { MMR, skeptic, critic, exemption, } \\
\text { objector, attitude, choice, fear, } \\
\text { opposition, autism, controversy, } \\
\text { hesitancy, perception, rumor, } \\
\text { rumour, avoidance, decision, } \\
\text { hesitation, phobia, awareness, } \\
\text { delay, intention, refusal, belief, } \\
\text { barrier, denial, knowledge, } \\
\text { rejection, dilemma, behavior, } \\
\text { behavior, misconception, } \\
\text { mandatory, reluctancy }\end{array}$ & 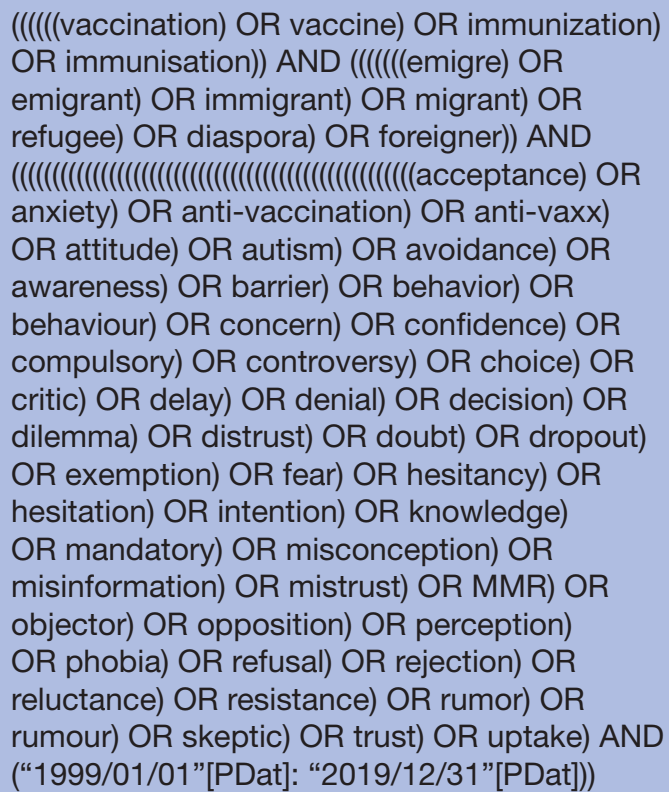 & 6887 \\
\hline
\end{tabular}

MMR, measles-mumps-rubella; PMC, PubMed Central.

the main determinant of underimmunisation in migrant populations is their reluctance to vaccinate. Political discourses that fuel prejudice and exclusion of the other, restrictive policies that deny good quality healthcare to the poor and access to universal health coverage to migrant populations, especially undocumented migrants, may represent far greater barriers to immunisation than vaccine hesitancy. ${ }^{34-36}$ However, we also believe that it is important to know the magnitude and nature of vaccine hesitancy in subpopulations like migrant communities because even very 'small clusters of non-vaccinators can have disproportionately adverse effects on herd immunity and epidemic spread'. ${ }^{37}$

\section{METHODS}

A methodological framework for scoping review was first outlined by Arksey and O'Malley, ${ }^{38}$ subsequently clarified by Levac and colleagues, ${ }^{39}$ and further elaborated by the Joanna Briggs Institute (JBI) ${ }^{33}$ JBI's elaboration of the framework contains 11 items: (1) title; (2) background; (3) review question/objective; (4) inclusion criteria; (5) types of participants; (6) concept; (7) context; (8) searching; (9) extracting and charting the results; (10) discussion; and (11) conclusions and implications for research and practice. We will apply this framework to organise our scoping review, supplementing it with recommendations from the Preferred Reporting Items for Systematic Reviews and Meta-Analyses extension for Scoping Reviews (PRISMA-ScR) checklist. ${ }^{40}$ This Methods section describes how we will address items 3-9 of the framework.

\section{Review question/objective}

Instead of review questions, we have stated three main review objectives at the end of the introduction section: (1) identifying evidence of vaccine hesitancy among migrant individuals and communities; (2) examining the extent and nature of the existing evidence; (3) determining the value of undertaking a full systematic review.

\section{Inclusion criteria}

Articles will be included if they focus on the theme of vaccine hesitancy and its variations (eg, vaccine acceptance, vaccine confidence, vaccine attitudes and behaviours, trust, distrust, concerns, perceptions and beliefs about vaccines and vaccination programmes). Articles will be included if published in the last two decades (January 1999-December 2019) and if the full text is available in either French or English. Articles will be excluded if written in any language other than the abovementioned languages and for which open-access automated translation programmes such as Google Translate are not suitable. Articles that do not focus on the human vaccine and that do not involve migrants will be excluded. Articles that focus on vaccine hesitancy in the wider population but whose results are disaggregated by immigration status will be included. Given that this is a scoping review, all evidence will be included, from single-case reports to 


\begin{tabular}{|c|c|}
\hline Data & Data description \\
\hline Study reference & $\begin{array}{l}\text { Name and surname of authors, } \\
\text { publication year }\end{array}$ \\
\hline Article type & $\begin{array}{l}\text { Quantitative, qualitative, mixed } \\
\text { methods, research, review, policy, } \\
\text { perspective, comment, letter, } \\
\text { unpublished report, media article }\end{array}$ \\
\hline Region of origin & $\begin{array}{l}\text { WHO region where country of study is } \\
\text { located }\end{array}$ \\
\hline Purpose & Overall aim and objectives of the study \\
\hline Population & $\begin{array}{l}\text { Main characteristics of populations, } \\
\text { communities and individuals } \\
\text { participating in the study }\end{array}$ \\
\hline $\begin{array}{l}\text { Country of } \\
\text { immigration }\end{array}$ & $\begin{array}{l}\text { Host country where migrant } \\
\text { participants reside }\end{array}$ \\
\hline $\begin{array}{l}\text { Country of national } \\
\text { origin }\end{array}$ & $\begin{array}{l}\text { Foreign country where migrants } \\
\text { or parents of second-generation } \\
\text { immigrants came from }\end{array}$ \\
\hline Country of transit & $\begin{array}{l}\text { Country where migrants may have } \\
\text { resided as refugee before relocating in } \\
\text { current host country }\end{array}$ \\
\hline Place of residence & $\begin{array}{l}\text { Neighbourhood, city or state where } \\
\text { migrant participants reside }\end{array}$ \\
\hline $\begin{array}{l}\text { Location of } \\
\text { immunisation centre }\end{array}$ & $\begin{array}{l}\text { Neighbourhood, city or state where } \\
\text { vaccination service is provided }\end{array}$ \\
\hline Religion & Main religion of migrants \\
\hline Native language & $\begin{array}{l}\text { First language primarily spoken by } \\
\text { migrants }\end{array}$ \\
\hline Ethnic/racial identity & Ethnic or racial group of migrants \\
\hline Comparator & $\begin{array}{l}\text { Outgroup members with whom } \\
\text { migrants are compared }\end{array}$ \\
\hline Concept & $\begin{array}{l}\text { Underlying determinants of vaccine } \\
\text { hesitancy explored by study }\end{array}$ \\
\hline Intervention & $\begin{array}{l}\text { Types of intervention attempted } \\
\text { or evaluated by study (eg, vaccine } \\
\text { administration, health communication, } \\
\text { policy, etc) }\end{array}$ \\
\hline Outcome & $\begin{array}{l}\text { Outcomes from intervention (eg, } \\
\text { increase, decrease or steady state in } \\
\text { vaccination rate) }\end{array}$ \\
\hline Vaccine & $\begin{array}{l}\text { Specific vaccine that is accepted, } \\
\text { delayed or rejected }\end{array}$ \\
\hline Findings & Relevant key findings from study \\
\hline
\end{tabular}

population-level studies and from primary research to review articles, policy reports and commentaries.

\section{Types of participants}

Target participants for this review are migrant populations, migrant communities and migrant individuals, including parents, expecting parents, childfree adults and children. We define migrants as including all individuals whose country of national origin (or whose parents' country of origin) is different from their country of residence, irrespective of the manner of entry and legal/ documented status in the host country. Further details on participants are provided in tables 1 and 2.

\section{Concept}

The concept or principal focus explored by this scoping review is vaccine hesitancy. As described in the previous section of this protocol, vaccine hesitancy is an inclusive concept that encompasses varying degrees of indecision about vaccination in general or certain vaccines in particular. Underlying factors of hesitancy include issues of confidence (do not trust vaccine or provider), complacency (do not perceive a need for a vaccine) and convenience (access) ${ }^{25}$ The final report from the SAGE Working Group on Vaccine Hesitancy states: 'Vaccinehesitant individuals may accept all vaccines but remain concerned about vaccines, some may refuse or delay some vaccines, but accept others; some individuals may refuse all vaccines'. ${ }^{24}$

\section{Context}

The context in this review could include the WHO regions of the studies, migrants' host country, their home or origin country, their cultural heritage (eg, religion, language and health-seeking traditions), their residential neighbourhood and the location/place where vaccination services are provided.

\section{Searching}

One of the most comprehensive systematic reviews of published literature on vaccine hesitancy to date was published in 2014 by members of the SAGE Working Group on Vaccine Hesitancy which includes one of the senior coauthors of this protocol. ${ }^{29}$ We will build on that 2014 publication, identifying relevant studies for our scoping review through several of the same databases included in that systematic review. All or most of the following databases will be searched from 1 January 1999 to 31 December 2019: Africa-Wide Information, Allied and Complementary Medicine, Cochrane Library, Cumulative Index of Nursing and Allied Health Literature, Embase, Index Medicus for the Eastern Mediterranean Region, International Bibliography of Social Sciences, Literature in the Health Sciences in Latin America and the Caribbean, Medline, Proquest Theses/Dissertations, PsycInfo and Web of Science. Given that we aim at examining both the scientific and grey literature, we will also search Google and Google Scholar in addition to the multidisciplinary mainstream and regional databases listed earlier. Last, we will contact the authors of all studies included in our synthesis to identify potential additional sources. We anticipate that the search for articles will be run across all databases between May and June 2020.

To the extent possible, we will abide by the PRISMA-ScR checklist to select relevant studies. Studies will be selected according to elements of the PICO (Participants, Intervention, Comparators and Outcome) model, ${ }^{40}$ as outlined in table 1. To capture multiple dimensions of 
vaccine hesitancy among migrants, the search strategy will include the non-exhaustive list of keywords and medical subject headings in table 2. Once retrieved, all articles will first be screened by title and abstract by at least two reviewers to ascertain their relevance. When in doubt, the full article will be scanned to further determine its relevance or decide on its exclusion. Reference lists of relevant articles will also be perused to ensure literature saturation.

\section{Extracting and charting the results}

It is standard in scoping reviews to illustrate the numerical outputs from the search and the inclusion decision process by means of a PRISMA flowchart. Our flowchart will clearly describe the review decision process, results from the search, removal of duplicate citations, study selection, full retrieval, any additions from reference list scanning and final summary presentation. In scoping review, 'charting the results' is an iterative process which involves the extraction of relevant data from all the studies included in the review. ${ }^{33}$ To enable consistency in data extraction among reviewers, we have developed a data charting template (table 3 ) to record characteristics of articles included and key data pertinent to the objectives of our review. We anticipate refinement (or consolidation) of this form after data from a small sample of studies (two to three) have been charted independently by two or more reviewers. We anticipate that results of the review will include both quantitative and qualitative data. We will present these results through summary narratives and visuals such as evidence 'maps' and tabular presentations.

\section{Protocol registration}

This protocol is not registered in the International Prospective Register of Systematic Reviews (PROSPERO) because this registry does not accept scoping reviews. ${ }^{41}$

\section{Patient and public involvement}

This review will be based solely on published articles and will not involve any patients or the public.

\section{ETHICS AND DISSEMINATION}

This review will be based on published works, and thus is exempted from formal ethical approval. It will be published in a peer-reviewed open-access journal to ensure wide dissemination.

\footnotetext{
Author affiliations

${ }^{1}$ Department of Health Services, University of Washington School of Public Health, Seattle, WA, United States

${ }^{2}$ Cochrane South Africa, South African Medical Research Council, Tygerberg, Western Cape, South Africa

${ }^{3}$ Department of Infectious Disease Epidemiology, London School of Hygiene and Tropical Medicine, London, UK

${ }^{4}$ Institute of Health Metrics and Evaluation, University of Washington, Seattle, WA, United States

${ }^{5}$ Department of Global Health, Stellenbosch University, Cape Town, South Africa
}

${ }^{6}$ School of Public Health and Family Medicine, University of Cape Town, Cape Town, South Africa

${ }^{7}$ Office of the Dean, Yale School of Public Health, Yale University, New Haven, CT, United States

Twitter Akhenaten Siankam Tankwanchi @Am3nhot3p, Heidi J Larson @ ProfHeidiLarson, Charles S Wiysonge @CharlesShey and Sten H Vermund @ SVermund

Contributors AST, HL and CSW: conceived the study. AST: wrote the first draft of the protocol. AJ, HL, CSW and SHV: revised the manuscript critically for important intellectual content.

Funding AJ and CSW are supported by the South African Medical Research Council. SHV is supported, in part, by a grant from the National Institutes of Health (P30MH062294).

Disclaimer The funders had no role in the design and writing of the protocol or the decision to submit it for publication.

Competing interests None declared.

Patient and public involvement Patients and/or the public were not involved in the design, or conduct, or reporting, or dissemination plans of this research.

Patient consent for publication Not required.

Provenance and peer review Not commissioned; externally peer reviewed.

Open access This is an open access article distributed in accordance with the Creative Commons Attribution Non Commercial (CC BY-NC 4.0) license, which permits others to distribute, remix, adapt, build upon this work non-commercially, and license their derivative works on different terms, provided the original work is properly cited, appropriate credit is given, any changes made indicated, and the use is non-commercial. See: http://creativecommons.org/licenses/by-nc/4.0/.

\section{ORCID iDs}

Akhenaten Siankam Tankwanchi http://orcid.org/0000-0002-6051-3292

Anelisa Jaca http://orcid.org/0000-0002-9814-8374

Charles S Wiysonge http://orcid.org/0000-0002-1273-4779

Sten H Vermund http://orcid.org/0000-0001-7289-8698

\section{REFERENCES}

1 United Nations Development Programme (UNDP). Human development report 2009. overcoming barriers: human mobility and development. New York: Palgrave Macmillan, 2009.

2 U.S. Citizenship and Immigration Services (USCIS). Applicability of medical examination and vaccination requirement. USCIS policy manual. Washington, DC: USCIS, 2017.

3 Center for Disease Control and Prevention. Vaccines for immigrants and refugees. Available: https://www.cdc.gov/vaccines/adults/recvac/immigrants-refugees.html [Accessed 18 Mar 2020].

4 Hong M-K, Varghese R, Jindal C, et al. Refugee policy implications of U.S. immigration medical screenings: a new era of Inadmissibility on health-related grounds. Int $J$ Environ Res Public Health 2017;14:1107.

5 World Health Organization (WHO). Promoting the health of refugees and migrants. draft global action plan, 2019 - 2023. Geneva: WHO, 2019.

6 Markkula N, Cabieses B, Lehti V, et al. Use of health services among international migrant children - a systematic review. Global Health 2018;14:52.

7 Mipatrini D, Stefanelli P, Severoni S, et al. Vaccinations in migrants and refugees: a challenge for European health systems. A systematic review of current scientific evidence. Pathog Glob Health 2017;111:59-68.

8 Awoh AB, Plugge E. Immunisation coverage in rural-urban migrant children in low and middle-income countries (LMICs): a systematic review and meta-analysis. J Epidemiol Community Health 2016;70:305-11.

9 Kennedy J. Populist politics and vaccine hesitancy in Western Europe: an analysis of national-level data. Eur J Public Health 2019;29:512-6.

10 Camargo K, Grant R. Public health, science, and policy debate: being right is not enough. Am J Public Health 2015;105:232-5.

11 Dyer O. Measles outbreak in Somali American community follows anti-vaccine talks. BMJ 2017;357:j2378.

12 Katz SL, Hinman AR. Summary and conclusions: measles elimination meeting, 16-17 March 2000. J Infect Dis;2004:S43-7. 
13 Fiebelkorn AP, Redd SB, Gallagher K, et al. Measles in the United States during the postelimination era. J Infect Dis 2010;202:1520-8.

14 Gastañaduy PA, Redd SB, Fiebelkorn AP, et al. Measles - United States, January 1-May 23, 2014. MMWR Morb Mortal Wkly Rep 2014;63:496-9.

15 Arciuolo RJ, Brantley TR, Asfaw MM, et al. Measles outbreak among members of a religious community-Brooklyn, New York, MarchJune 2013. MMWR MMWR Morb Mortal Wkly Rep 2013;752.

16 Gahr P, DeVries AS, Wallace G, et al. An outbreak of measles in an undervaccinated community. Pediatrics 2014;134:e220-8.

17 Leslie TF, Delamater PL, Yang YT. It could have been much worse: the Minnesota measles outbreak of 2017. Vaccine 2018;36:1808-10.

18 Hewitt A, Hall-Lande J, Hamre K, et al. Autism spectrum disorder (ASD) prevalence in Somali and Non-Somali children. J Autism Dev Disord 2016;46:2599-608.

19 Deer $B$. How the case against the MMR vaccine was fixed. BMJ 2011;342:c5347.

20 Godlee F, Smith J, Marcovitch H. Wakefield's article linking MMR vaccine and autism was fraudulent. BMJ 2011;342:c7452.

21 Vainio K, Rønning K, Steen TW, et al. Ongoing outbreak of measles in Oslo, Norway, January-February 2011. Euro Surveill 2011:1-3.

22 Mupandawana ET, Cross R. Attitudes towards human papillomavirus vaccination among African parents in a City in the North of England: a qualitative study. Reprod Health 2016;13:97.

23 Hickler B, Guirguis S, Obregon R. Vaccine special issue on vaccine Hesitancy. Vaccine 2015;33:4155-6.

24 World Health Organization. Report of the SAGE Working group on vaccine Hesitancy. Geneva, Switzerland: WHO, 2014.

25 MacDonald NE. Definition Vaccine hesitancy Scope and determinants. Vaccine 2015;33:4161-4

26 Goldstein S, MacDonald NE, Guirguis S, et al. Health communication and vaccine hesitancy. Vaccine 2015;33:4212-4.

27 Salmon DA, Dudley MZ, Glanz JM, et al. Vaccine hesitancy: causes, consequences, and a call to action. Vaccine 2015;33 Suppl 4:D66-71.

28 Williams SE. What are the factors that contribute to parental vaccinehesitancy and what can we do about it? Hum Vaccin Immunother 2014;10:2584-96.
29 Larson HJ, Jarrett C, Eckersberger E, et al. Understanding vaccine hesitancy around vaccines and vaccination from a global perspective: a systematic review of published literature, 2007-2012. Vaccine 2014;32:2150-9.

30 Bedford H, Attwell K, Danchin M, et al. Vaccine hesitancy, refusal and access barriers: the need for clarity in terminology. Vaccine 2018;36:6556-8.

31 Peretti-Watel P, Larson HJ, Ward JK, et al. Vaccine hesitancy: Clarifying a theoretical framework for an ambiguous notion. PLoS Curr 2015;7:6844c80ff9f5b273f34c91f71b7fc289.

32 World Health Organization. Ten threats to global health in 2019,Geneva, 2019. Available: https://www.who.int/emergencies/ ten-threats-to-global-health-in-2019 [Accessed 18 Mar 2020].

33 Peters MDJ, Godfrey CM, Khalil H, et al. Guidance for conducting systematic scoping reviews. Int J Evid Based Healthc 2015;13:141-6

34 Ottersen OP, Dasgupta J, Blouin C, et al. The political origins of health inequity: prospects for change. Lancet 2014;383:630-67.

35 Onarheim KH, Melberg A, Meier BM, et al. Towards universal health coverage: including undocumented migrants. BMJ Glob Health 2018;3:e001031.

36 Abubakar I, Aldridge RW, Devakumar D, et al. The UCL-Lancet Commission on migration and health: the health of a world on the move. Lancet 2018;392:2606-54.

37 Larson HJ, de Figueiredo A, Xiahong Z, et al. The state of vaccine confidence 2016: global insights through a 67-country survey. EBioMedicine 2016;12:295-301.

38 Arksey H, O'Malley L. Scoping studies: towards a methodological framework. Int J Soc Res Methodol 2005;8:19-32.

39 Levac D, Colquhoun H, O'Brien KK. Scoping studies: advancing the methodology. Implement Sci 2010;5:69.

40 Tricco AC, Lillie E, Zarin W, et al. PRISMA extension for scoping reviews (PRISMA-ScR): checklist and explanation. Ann Intern Med 2018;169:467-73.

41 National Institute of Health Research. International prospective register of systematic reviews: inclusion criteria. Available: https:// www.crd.york.ac.uk/prospero/\#guidancenotes [Accessed 18 Mar 2020]. 